\title{
Assessment of Micronuclei Frequency in Individuals with a Habit of Tobacco Chewing by Means of Exfoliated Oral Buccal Cells
}

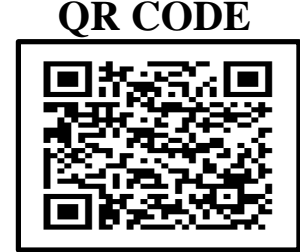

\section{SWATI PARHAR ${ }^{1}$, AMANI MAHAJAN²}

INTRODUCTION: Majority of cancers are diagnosed at an advanced stage resulting in poor prognosis and survival rates among patients. Hence early diagnosis of oral cancers seems to be the need of the hour. Analysis of exfoliated buccal cell micronuclei (MN) is a sensitive method of monitoring genetic damage.

AIM: The present study has been carried out with an objective to evaluate the genotoxic effects of tobacco chewing by means of micronucleus assay in exfoliated cells of buccal mucosa.

MATERIALS AND METHOD: This cross sectional study was carried out in Department of Oral Pathology, Swami Devi Dyal Hospital And Dental College, Golpura, Barwala, Panchkula. The study population comprised of a total of 50 subjects, divided into five groups: Group 1 comprising of 10 age and sex matched healthy subjects without any habits as controls, Group 2 comprising of 10 subjects with a history of chewing tobacco. Group 3 comprising of 10 subjects with a history of chewing tobacco and cigarette smoking, Group 4 comprising of 10 subjects with a history of chewing tobacco and drinking and Group 5 comprising of 10 subjects with a history of chewing tobacco, smoking and drinking. Oral exfoliated cells were obtained from buccal mucosa of the subjects, slides were prepared from each subject stained with stain respectively.

RESULTS: The mean numbers of micronuclei in group 1 were $7.86 \pm 6.7$, Group 2 were $63.37 \pm 10.01$, Group 3 were $65.49 \pm 12.32$, Group 4 were $68.22 \pm 11.11$ and Group 5 were $69.43 \pm 10.71$. On comparison we observed that the difference in Mean micronuclei frequency among all the 5 study groups came to be statistically also highly significant $\left(\mathrm{p}<0.0001^{*}\right)$

CONCLUSION: Micronuclei assay is an effective tool that reflects severity of disease. Even though tobacco induced cancers are preventable banning the use of tobacco has not been possible for social and political reasons.

KEYWORDS: Cytology, Tobacco, Oral Mucosa

\section{INTRODUCTION}

Oral cancer is world's tenth most common cancer. Low-and middle-income countries bear the global burden of tobacco use. With greater than 300 million smokers, China is the world 's largest tobacco marketer, led by India with over 100 million. ${ }^{1}$ Oral cancer is the third most significant group of malignancies in India. ${ }^{2}$

In India chewing tobacco rather than smoking tobacco is common, especially in rural areas. 75,000 to 80,000 new cases of oral cancer were observed in 2012 and this proportion is expected to grow further by 2025. Most of these cancers are usually identified at an advanced stage, which results in poor patient prognosis and survival. Therefore, the need for an hour appears is early and timely diagnosis of oral cancer.

The analysis of exfoliated oral cell micronuclei (MN) is a sensitive method of monitoring genetic damage in the human population. First proposed by Stitch et al, due to its low cost, minimal invasiveness and ease of storage and slide preparation, this test continues to gain popularity to be a biomarker to detect genetic damage. ${ }^{3}$
Micronuclei are characterized as a cytoplasmic chromatin mass that are microscopically observable, with round to oval shape and located near the nucleus. It is a tiny extranucleus isolated from the main one during the process of cellular division. It is formed during the metaphase/anaphase transition phase during cell division. These structures have similar appearance to those structures which can be observed in the cellular nuclei during of interphase. ${ }^{4,5}$

Therefore, in the present study we aimed to evaluate the genotoxic effects of tobacco chewing by means of micronucleus assay in exfoliated cells of buccal mucosa.

\section{MATERIAL AND METHODS}

This cross-sectional study was carried out in Department of Oral and Maxillofacial Pathology, Swami Devi Dyal Hospital and Dental College, Golpura, Barwala, Panchkula. The study population included of a total of 50 subjects, divided into five groups:

C Swati Parhar et al. This is an open access article distributed under the terms of the Creative Commons Attribution License CC-BY-NC 4.o, which permits unrestricted use, distribution and reproduction in any medium, provided the use is not commercial and the original author(s) and source are cited. 
Group 1: Comprising of 1o healthy subjects of similar age and sex and without any habits as controls

Group 2: Comprising of 10 subjects with a history of chewing tobacco

Group 3: Comprising of 10 subjects presenting with history of chewing tobacco and cigarette smoking

Group 4: Comprising of 10 subjects presenting with history of chewing tobacco and drinking

Group 5: Comprising of 10 subjects presenting with history of chewing tobacco, smoking and drinking

A written informed consent was taken from all the subjects. Prior approval from concerned institutional ethical committee was taken.

Inclusion criteria: The inclusion criteria for smokers and tobacco chewers were the use of cigarettes and/or tobacco for atleast last six months.

Exclusion criteria: Subjects with a history of recent viral infection, Subjects with use of antibiotics within 2 months before sample collection, Subjects with recent history of exposure to potential genotoxic agents, including $\mathrm{X}$ rays, chemotherapy and potential occupational exposures and Subjects with any oral pathological lesions were exempted from our study. Sample, staining and cytological analysis: Prior to sampling each subject was instructed to rinse their mouth properly using tap water. Oral Smears comprising of the exfoliated oral epithelial cells of buccal mucosa of control and study group were obtained using a moistened wooden spatula. 2 slides were prepared for each subject. One Slide was kept aside to air dry and stained with geimsa and the other slide was directly fixed in a solution of $95 \%$ alcohol and then stained with $\mathrm{H} \& \mathrm{E}$ stain.

At minimum of 1,000 cells were observed for each subject and MN frequency was scored asper the criteria of Tolbert et al. The suspected nucleus is required to meet the following criteria in order to be considered as Micronucleus: (a) rounded, smooth perimeter suggestive of membrane; (b) less than third the diameter of the main nucleus, but large enough to discriminate shape and color; (c) staining intensity similar to that of nucleus; (d) same focal plane as nucleus (figure 1 ).

Statistical analysis: Statistical analysis was done using SPSS version 20. The findings are presented as mean and standard deviation. To analyse the mean difference of micronuclei among the three groups, one way

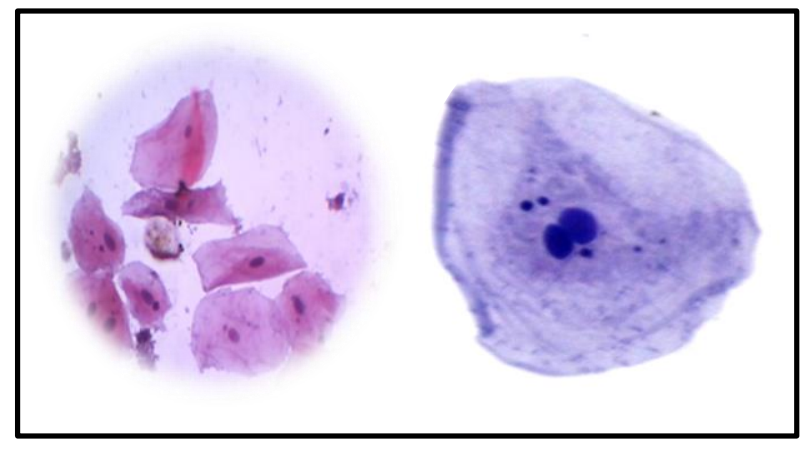

Figure 1. Buccal epithelial cell with micronuclei

ANOVA was performed and p value of less than 0.05 was considered statistically significant.

\section{RESULTS}

The results of the present study shows that, mean age with standard deviation of all the study groups came to be $54.87 \pm 12.11$ years for group 1, 63.37 \pm 10.01 for group 2, $65.49 \pm 12.32$ years for group 3, 65.49 \pm 12.32 years for group 4 and $69.43 \pm 10.71$ for group 4 (table 1 ). All the subjects included in the present study were males.

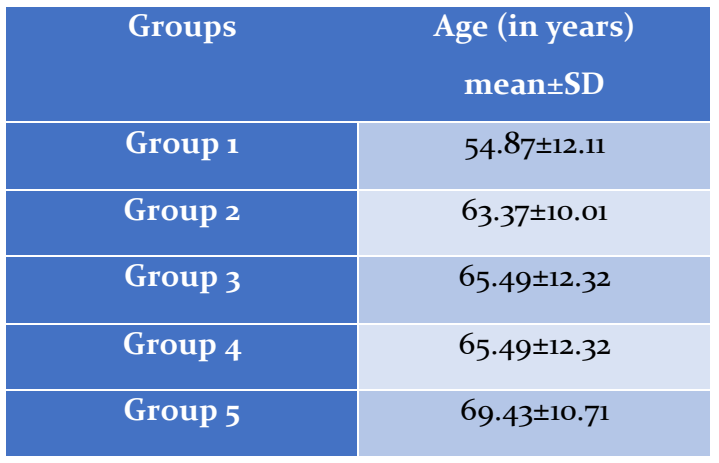

Table 1. Age distribution of study subjects

Mean micronuclei frequency observed in group 1 came to be $7.86 \pm 6.7$, group 2 had $16.4 \pm 8.3$, group 3 had $21.37 \pm 8.9$, group 4 had $23.22 \pm 8.8$ and group 5 had 26.57 \pm 9.2 . On comparison we observed that the difference in Mean micronuclei frequency among all the 5 study groups came to be statistically also highly significant $\left(\mathrm{p}<0.0001^{*}\right)($ table 2$)$.

\section{DISCUSSION}

The Micronuclei (MN) assay may be an outstanding biomarker to detect chromosome loss or mitotic spindle failure caused by aneugenic mechanisms. In several studies, the effectiveness of this test for this reason has been highlighted.4,6,7 The present study 


\begin{tabular}{|c|c|c|}
\hline Groups & Mean \pm SD & P value \\
\hline Group 1 & $7.86 \pm 6.7$ & \\
\hline Group 2 & $16.4 \pm 8.3$ & 0.00o1 \\
\hline Group 3 & $21.37 \pm 8.9$ & \\
\hline Group 4 & $23.22 \pm 8.8$ & \\
\hline Group 5 & $26.57 \pm 9.2$ & \\
\hline
\end{tabular}

Table 2. Comparison of mean number of micronucleated cells using by one way ANOVA

aimed to evaluate the genotoxic effects of tobacco chewing with the help of micronucleus assay in exfoliated cells of buccal mucosa.

The use of tobacco (either by smoking or chewing) has adverse effects on Buccal mucosa. ${ }^{3}$ Nicotine, tar and polycyclic hydrocarbons are the main toxic components of tobacco. This study found that tobacco has major genotoxic effects on the buccal epithelial cells in both smoking and smokeless types, as demonstrated by a higher micronuclei level in tobacco chewers and tobacco chewers with a smoking habit. These findings are fully in agreement with other research. ${ }^{8,9}$

Kassie $\mathrm{F}$ et al. $^{10}$ examined the synergistic effect of the behaviours of chewing tobacco and also smoking tobacco on micronucleus induction in oral epithelial cells, the results of which are in accordance with our research.

Explaining the reason behind the genotoxicity, Livingston GK et al. ${ }^{11}$ stated that, tobacco soluble saliva compounds may reach the basal layer of the epithelium and interfere with the reproductive system of the underlying actively dividing cell population , resulting in genotoxicity and nuclear aberration formation.

Nagler R et al. ${ }^{12}$ also explained that the genotoxicity potential is increased by the associations between both the active reactive metals of saliva and between the less reactive free radicals throughout tobacco chewing and smoking.

In their research, Palaskar et al. ${ }^{13}$ found that the occurrence of micronuclei is greater in persons using smokeless tobacco in comparison to the ones using smoking type of tobacco. The oral buccal cell micronucleus is considered a hallmark of chromosomal damage which is usually caused due to genotoxic substances derived from nicotine, tobacco, and alcohol-related substances. A symbol of such chromosomal damage is the production of micronucleated cells due to toxic effects of such carcinogens.

Adverse effects are usually seen in oral mucosal cells as it is effortlessly accessible tissue that can be collected easily without causing patients stress. ${ }^{14}$ The increased incidence of nuclear changes in tobacco and alcoholusing oral mucosal cells suggests a high-risk oral cancer population. Thus evaluation of micronucleus within the oral epithelial cells seems to be a suitable means for the research purpose.

\section{CONCLUSION}

The Micronuclei assay is an efficient method that represents disease severity. The micronucleus count is used as a non-invasive method for diagnosis, patient education, mass population screening, and also for testing the efficacy of treatment.

\section{REFERENCES}

1. Giovino GA, Mirza SA, Samet JM, Gupta PC, Jarvis $\mathrm{MJ}$, Bhala $\mathrm{N}$ et al. Tobacco use in 3 billion individuals from 16 countries: An analysis of nationally representative cross-sectional household surveys. Lancet 2012; 380:668-79.

2. Elango JK, Gangadharan P, Sumithra S, Kuriakose MA. Trends of head and neck cancers in urban and rural India. Asian Pacific J Cancer Preven. 2006;7(1):108-12.

3. Agrawal V, Dubey I, Mishra KB. Evaluation of micronucleus frequency in oral exfoliated buccal mucosa cells of smokers and tobacco chewers: a comparative study. Int J Res Med Sci. 2016;4:3130-3.

4. Tolbert PE, Shy CM, Allen JW. Micronucleus and other nuclear anomalies in buccal smears: Methods development . Mut Res. 1991;271:69-77.

5. Dosi T, Gupta D, Hazari A, Rajput R, Chauhan P, Rajapuri AS. Assessment of micronuclei frequency in individuals with a habit of tobacco by means of exfoliated oral buccal cells. J Int Soc Prevent Communit Dent. 2016;6:S143-7.

6. Cavallo D, Ursini CL, Perniconi B, Francesco AD, Giglio M, Rubino FM, Marinaccio A, Iavicoli S. Evaluation of genotoxic effects induced by exposure to antineoplastic drugs in lymphocytes and exfoliated cells of oncology nurses and pharmacy employees. 
Mutation Research 2005;587:45-51.

7. Salama SA, Serrana M, Au WW. Biomonitoring using accessible human cells for exposure and health risk assessment. Mutation Research 1999;436:99-112.

8. Gabriel HE, Crott JW, Ghandour H, Dallal GE, Choi SW, Keyes MK, Jang H. Chronic cigarette smoking is associated with diminished folate status, altered folate form distribution, and increased genetic damage in the buccal mucosa of healthy adults. Am J Clin Nutr. 2006;41:835-41.

9. Naderi NJ, Farhadi S, Sarshar S. Micronucleus assay of buccal mucosa cells in smokers with the history of smoking less and more than 10 years. Indian J Pathol Microbiol. 2012;55:433-8.

10. Kassie F, Darroudi F, Kundi M, Schulte-Hermann R, Khat KS. Catha edulis consumption causes genotoxic effects in humans. International Journal of Cancer. 2001;92:329-32.

11. Livingston GK, Reed RN, Olson BL, Lockey JE. Induction of nuclear aberrations by smokeless tobacco in epithelial cells of human oral mucosa. Environ Mol Mutagen. 1990;15:136-44.

12. Nagler R, Dayan D. The dual role of saliva in oral carcinogenesis. Oncology 2006;71:10-7.

13. Palaskar S, Jindal C. Evaluation of micronuclei using Papanicolaou and may Grunwald-Giemsa stain in individuals with different tobacco habits: a comparative study. J Clin Diagn Res. 2011;4:3607-13. 14. Bansal H, Sandhu VS, Bhandari R, Sharma D. Evaluation of micronuclei in tobacco users: A study in Punjabi population. Contemp Clin Dent. 2012;3:184-7. https://doi.org/10.4103/0976-237X.96825

Cite this article as:

Parhar S, Mahajan A. Assessment of Micronuclei Frequency in Individuals with

a Habit of Tobacco Chewing by Means of Exfoliated Oral Buccal Cells. Int

Healthc Res J. 2020;4(7):OR15-OR18. https://doi.org/10.26440/IHRJ/0407.10277

\section{AUTHOR AFFILIATIONS: (*Corresponding Author)}

1. Reader

2. Senior Lecturer

Department of Oral Pathology, Swami Devi Dyal Hospital and Dental College, Barwala, Panchkula, India 